\title{
Combination treatment in the management of type 2 diabetes: focus on vildagliptin and metformin as a single tablet
}

\author{
Serge Halimi' \\ Anja Schweizer ${ }^{2}$ \\ Biljana Minic ${ }^{2}$ \\ James Foley ${ }^{3}$ \\ Sylvie Dejager ${ }^{4}$ \\ 'University Hospital of Grenoble \\ College of Medicine, Diabetes and \\ Endocrine department, Grenoble, \\ France; ${ }^{2}$ Novartis Pharma AG, \\ Basel, Switzerland; ${ }^{3}$ Novartis \\ Pharmaceuticals Corporation, \\ E. Hanover, NJ, ${ }^{4}$ Novartis \\ Pharmaceuticals Corporation, Rueil \\ Malmaison, France.
}

\begin{abstract}
Vildagliptin is a potent and selective inhibitor of dipeptidyl peptidase-IV (DPP-4), orally active, that improves glycemic control in patients with type 2 diabetes (T2DM) primarily by enhancing pancreatic ( $\alpha$ and $\beta$ ) islet function. Thus vildagliptin has been shown both to improve insulin secretion and to suppress the inappropriate glucagon secretion seen in patients with T2DM. Vildagliptin reduces $\mathrm{HbA}_{1 \mathrm{c}}$ when given as monotherapy, without weight gain and with minimal hypoglycemia, or in combination with the most commonly prescribed classes of oral hypoglycemic drugs: metformin, a sulfonylurea, a thiazolidinedione, or insulin. Metformin, with a different mode of action not addressing $\beta$-cell dysfunction, has been used for about 50 years and still represents the universal first line therapy of all guidelines. However, given the multiple pathophysiological abnormalities in T2DM and the progressive nature of the disease, intensification of therapy with combinations is typically required over time. Recent guidelines imply that patients will require pharmacologic combinations much earlier to attain and sustain the increasingly stringent glycemic targets, with careful drug selection to avoid unwanted adverse events, especially hypoglycemia. The combination of metformin and vildagliptin offers advantages when compared to currently used combinations with additive efficacy and complimentary mechanisms of action, since it does not increase the risk of hypoglycemia and does not promote weight gain. Therefore, by specifically combining these agents in a single tablet, there is considerable potential to achieve better blood glucose control and to improve compliance to therapy.
\end{abstract}

Keywords: type 2 diabetes, dipeptidyl peptidase-4, HbA ${ }_{1 c}$, GLP-1, incretin hormones, Eucreas $^{\circledR}$

\section{Management of type 2 diabetes: use of metformin and the role of combination treatment}

Type 2 diabetes (T2DM) is a chronic and complex disease which involves multiple pathophysiological defects, including impaired islet function and insulin resistance, resulting in impaired glucose tolerance and inappropriately high fasting hepatic glucose production. While insulin resistance remains essentially unchanged over time, the deficit in islet function is a progressive process with quantitative and qualitative abnormalities in insulin and glucagon secretion kinetics, paralleled by a substantial reduction in the maximum capacity to secrete insulin. These defects in islet function are present early on and worsen with the natural history of the disease (Butler et al 2003; Nathan et al 2007; Virally et al 2007). Indeed, most individuals who are insulin resistant never develop T2DM because normal islets adapt to insulin resistance both by increasing glucose-potentiated insulin secretion (Kahn et al 1993) and by increasing $\alpha$-cell sensitivity to the suppressive effects of glucose (Ahren 2006). Thus, the 
first patent characteristic of T2DM is inadequate islet compensation rather than absolute hypoinsulinemia or absolute hyperglucagonemia (Ahren et al 2008).

Despite clear evidence that maintenance of glycemic levels as close to normal as possible reduces the risk of diabetic complications, optimal control is seldom achieved and maintained in patients with T2DM (Brown et al 2004; Koro et al 2004). While all oral antidiabetic agents initially lower blood glucose effectively, none of them are able to address all the anomalies involved in the pathogenesis of T2DM, to stop the decline in beta-cell function, and to achieve durable glycemic control (Cook et al 2007).

Established management of T2DM starts with lifestyle changes, ie, introducing a healthier diet and increasing physical activity in order to improve glucose utilization and promote weight loss. This is accompanied by rapid or even concomitant introduction of an oral antidiabetic agent. Metformin is widely used as the first-line antidiabetic drug of choice (Consoli et al 2004; Halimi 2006). Metformin reduces hepatic glucose output, primarily by inhibiting gluconeogenesis, and, to a lesser extent, increases tissue sensitivity to insulin (Stumvoll et al 1995). Beneficial clinical properties of metformin include weight control (Golay 2007), a low risk of hypoglycemia and favorable effects on the lipid profile and the fibrinolytic pathway (Bailey and Turner 1996; Goodarzi and Bryer-Ash 2005). Metformin was reported to be equally effective in lowering glucose in non-obese and obese patients and can thus be used independent of an individual's BMI (Donnelly et al 2006). More importantly, it is the only drug which has demonstrated beneficial effects on cardiovascular events, as reported in the UKPDS substudy of overweight patients (UKPDS 34 1998). In this study, metformin was also associated with reduced all cause mortality, which was not seen in patients with equally well controlled blood glucose treated with sulfonylureas or insulin.

Metformin is therefore recommended by all guidelines as first-line therapy for T2DM. The International Diabetes Federation (IDF) suggests to use metformin in all cases inadequately controlled by non-pharmacological treatments (IDF, on line) while a recent consensus document of the American Diabetes Association (ADA) and the European Association for the Study of Diabetes (EASD) recommends to prescribe metformin at diagnosis, together with lifestyle interventions (Nathan et al 2006, 2008).

Upon progression of the disease, progressive loss of $\beta$-cell function and mass makes it difficult for patients to maintain glycemic control with monotherapy. In the UKPDS only about $50 \%$ of patients were still adequately controlled on monotherapy after 3 years (Turner et al 1999) (UKPDS-49). Even if somewhat better durability of glycemic control was achieved with TZD over 4 years in the ADOPT trial (Kahn et al 2006), high rates of secondary failure have been reported with all current oral hypoglycemic drugs (OADs), including following successful initial metformin therapy (Nichols et al 2006).

As a result, combination therapy involving agents with complementary mechanism of action is the next logical step in the management of T2DM. Established treatment options for metformin monotherapy failure include the addition of sulfonylureas (or glinides), thiazolidinediones, acarbose, or insulin. Since metformin lowers plasma glucose without affecting insulin secretion, it is often combined with an agent stimulating insulin secretion, like a sulfonylurea. Adding a sulfonylurea to metformin has thus been the conventional and the gold standard combination therapy for decades. However, while previous therapeutic goals made this combination quite attractive, the lower glycemic targets for intensification of therapy substantially increase the risk of hypoglycemia (particularly in patients with mild hyperglycemia or in the older and more fragile patients) resulting in symptoms or increased food intake to avoid or treat them. Therefore, the need for more glucose-sensitive agents as alternative combination therapies was warranted.

Recently, newer agents, which induce a glucosedependent stimulation of insulin secretion became available and can provide an attractive alternative for use in combination with metformin. Such a novel therapy for T2DM is based on pharmacological inhibition of the enzyme dipeptidyl peptidase IV (DPP-4), which is responsible for the rapid inactivation of the incretin hormones glucagon-like peptide-1 (GLP-1) and glucose-dependent insulinotropic peptide (GIP) (Langley et al 2007). These intestinally derived peptides are released rapidly after eating, ie, in the presence of glucose or nutrients in the gut.

By stabilizing endogenous incretin hormones at physiological concentrations, DPP-4 inhibitors increase the sensitivity to glucose of both insulin and glucagon secretion (ie, increase insulin secretion and suppress glucagon secretion in a glucose-dependent manner), thereby lowering glucose levels. DPP-4 inhibitors are thus the first oral agents addressing the dual $\alpha$ - and $\beta$ - islet cells dysfunction present in T2DM.

This article provides an overview of the characteristics and combined anti-diabetic effects of the DPP4 inhibitor vildagliptin and metformin. 


\section{Pharmacokinetics/ \\ Pharmacodynamics (Pk/Pd) and mode of action (MoA) of metformin and vildagliptin, and rationale for their use in combination PK/PD and MoA of metformin}

Metformin is absorbed mainly from the small intestine, with a $60 \%$ bioavailability; the plasma half life is estimated at 1.5-4.9 hours. The drug is not significantly metabolized, and $90 \%$ is eliminated unchanged in urine in 12 hours by glomerular filtration and tubular secretion. It is distributed in most tissues, with higher concentrations in liver, kidneys, salivary glands and the intestinal walls. The drug can be removed by hemodyalisis.

Metformin has been available for treating diabetes since the 1950s, but despite decades of medical use, the mechanism of action of the drug at the molecular level is still not fully understood but is related to an action on AMP kinase (Goodarzi and Bryer-Ash 2005).

The glucose-lowering effect of metformin is mainly due to decreased basal hepatic glucose output and -to a lesser extent- enhanced peripheral glucose uptake (with muscle as its main site of action). The latter action on muscles is likely indirect and explained by the overall improved metabolic state. Additional actions that contribute to the glucoselowering effect are the increased intestinal use of glucose and decreased fatty acid oxidation (Bailey and Turner 1996).

The most feared and widely publicized adverse effect of biguanide therapy is lactic acidosis, likely resulting from the action of biguanides to interfere with non-oxidative glucose metabolism. Lactic acidosis could occur in energy-compromised individuals leading to increased lactate production and/or reduced lactate clearance, such as in liver disease, renal dysfunction or other illness causing tissue hypoxia (such as cardiac or respiratory dysfunction). It has a high mortality, but is extremely rare with metformin, the overall incidence being estimated at one case per 30,000 patient-years. This rate of lactic acidosis events is actually almost similar to that reported in patients with T2DM not taking metformin (Brown et al 1998) indicating that lactic acidosis occurs in metformin-treated patients when energy metabolism is further altered in patients where it was already severely compromised (Tahrani et al 2007).

The most common dose-limiting adverse effects of metformin are gastrointestinal (abdominal discomfort, metallic taste and anorexia, nausea or diarrhea) but these effects are minimized with gradual upward titration and concomitant administration with meals, overall leading to drug discontinuation in less than $5 \%-10 \%$ of the patients (Bailey and Turner 1996; Goodarzi and Bryer-Ash 2005). However gastrointestinal discomfort is often the single factor that prevents the use of higher, more efficacious doses of metformin.

\section{PK/PD and MoA of vildagliptin}

Vildagliptin is well and rapidly absorbed after oral administration. About $70 \%$ of the orally administered vildagliptin is metabolized, hydrolysis being the main pathway, and renal excretion being the main route of elimination (85\%), with some of the oral dose excreted in the urine as unchanged drug (23\%). Food ingestion does not alter the pharmacokinetics of vildagliptin (Sunkara et al 2007). Vildagliptin does not inhibit or induce the major P450 enzymes and shows no drug interactions with commonly used medication (such as glyburide, metformin, pioglitazone, digoxin, warfarin, simvastatin, valsartan, amlodipine, ramipril) (Ayalasomayajula et al 2007; El Ouaghlidi et al 2007; He et al 2007a, b). Age, gender, BMI, and race do not affect the pharmacokinetics of vildagliptin (He et al 2007c, d, e).

Vildagliptin selectively inhibits DPP- 4 activity (Burkey et al 2006), resulting in increased levels (2- to 4-fold) of the two key glucoregulatory incretin hormones GLP-1 and GIP, allowing the pancreatic islet cells to better sense and more appropriately respond to raised glucose levels (Ahren et al 2005; Mari et al 2005).

The increased levels of active endogenous incretin hormones result in better post-prandial and fasting glucose control by stimulating insulin secretion, reducing glucagon levels and suppressing overnight hepatic glucose production, which all contribute to the clinical effect to lower $\mathrm{HbA}_{10}$ (Ahren et al 2004b, 2005; Balas et al 2007).

Further evidence for an improvement of islet function with vildagliptin, with an increase of both $\alpha$ - and $\beta$-cell responsiveness to glucose, come from a number of recent studies (Azuma et al 2007; Pratley et al 2007b; Mari et al 2007). In addition, vildagliptin treatment leads to a more efficient $\beta$-cell insulin processing, providing further evidence for an amelioration of the abnormal $\beta$-cell function in patients with T2DM (Ahren et al 2007). Previous data in rodents showed that vildagliptin increases pancreatic $\beta$-cell mass by markedly stimulating $\beta$-cell replication and inhibiting apoptosis (Duttaroy et al 2005), similar to the beneficial effects reported for parenterally administered GLP-1 agonists (Tourrel et al 2002). These animal data on beta cell protection still need to translate into durable glycemic control 
in humans, which can only be demonstrated in long term clinical trials.

These primary effects of vildagliptin to enhance incretin hormone levels also lead to improved insulin mediated glucose disposal which may be due in part to reduced glucose toxicity and in part to reduced stored triglycerides in muscle and liver (Azuma et al 2007). A similar improvement in insulin sensitivity and $\beta$-cell function, leading to improved postprandial glycemia, has recently been shown in subjects with impaired fasting glucose after 6 weeks of treatment with vildagliptin $100 \mathrm{mg} /$ day (Utzschneider et al 2008). Furthermore, the known effects of vildagliptin on incretin levels and islet function in type 2 diabetes were reproduced in another study conducted in 179 subjects with impaired glucose tolerance over 12 weeks, with a $32 \%$ reduction in postprandial glucose excursions and no evidence of hypoglycemia or weight gain (Rosenstock et al 2007c).

Vildagliptin shows no action on gastric emptying or any evidence for delayed glucose absorption or delayed appearance of drugs co-administered in interaction studies (Vella et al 2007).

Interestingly, treatment with vildagliptin for 4 weeks improved postprandial plasma triglyceride after a fat-rich meal, and this was achieved mainly through a decrease in intestinally derived apo B-48-containing particles. These results indicate that vildagliptin treatment reduces postprandial atherogenic TRLs in the circulation and suggest that it may protect against weight gain in patients with T2DM by extracting less fat from the gut (Matikainen et al 2006).

The clinical profile of vildagliptin has been extensively assessed in the development program, providing evidence of its glucose-lowering efficacy across a wide range of clinical uses: as monotherapy or initial combination therapy in treatment-naive patients (Dejager et al 2007; Pi-Sunyer et al 2007; Rosenstock et al 2007 a, b; Schweizer et al 2007), as add-on therapy with the most commonly prescribed classes of oral hypoglycemic drugs (Bosi et al 2007; Garber et al $2007 \mathrm{a}, \mathrm{b})$, and in combination with insulin in patients with long-standing disease (Fonseca et al 2007). In monotherapy, vildagliptin produced consistent reductions from baseline in $\mathrm{HbA}_{1 \mathrm{c}}$ of approximately $1 \%$, sustained out to one year, was weight-neutral and well-tolerated, and had a low incidence of hypoglycemia and no episodes of severe hypoglycemia. Vildagliptin $100 \mathrm{mg}$ daily was as effective as rosiglitazone $8 \mathrm{mg}$ daily without the weight gain (Rosenstock et al 2007b). When compared with metformin $2000 \mathrm{mg}$ daily, statistical noninferiority was not established but treatment with vildagliptin $100 \mathrm{mg}$ daily for 1 year reduced $\mathrm{HbA}_{1 \mathrm{c}}$ by
$1.0 \%(\mathrm{p}<0.001)$ with a more favorable gastrointestinal (GI) tolerability than metformin (Schweizer et al 2007). Furthermore, the efficacy and safety profiles of vildagliptin in elderly patients (who had a high prevalence of co-morbidities and mild renal insufficiency) were comparable to those in younger patients, including a very low $(0.8 \%)$ incidence of hypoglycemia and no severe hypoglycemic episode (Pratley et al 2007a). In this regard, a recent study of vildagliptin added to existing insulin therapy is interesting: hypoglycemia was significantly less frequent and less severe with vildagliptin than with placebo, despite improved glycemic control in those receiving vildagliptin (Fonseca et al 2007). In addition, recent data further confirmed the low hypoglycemic risk at the other end of the disease spectrum. In recently diagnosed patients with mild hyperglycemia $\left(\mathrm{n}=306\right.$; baseline $\mathrm{HbA}_{1 \mathrm{c}} \approx$ $6.7 \%, \mathrm{FPG} \approx 7.1 \mathrm{mmol} / \mathrm{L}$ and nearly half of the patients over age 65) 52-week treatment with vildagliptin elicited a modest but statistically significant reduction in A1C $(-0.3 \%)$, primarily due to a reduction of postprandial glucose and at least in part reflecting improved beta-cell function. Treatment with vildagliptin was weight neutral $(-0.5 \mathrm{~kg}$ from baseline) and was well tolerated with no episode of hypoglycemia over one year in the vildagliptin group (Scherbaum et al 2007). This low hypoglycemic potential of vildagliptin likely reflects the glucose-dependent nature of both the insulinotropic and the glucagonostatic effects of GLP-1.

\section{Rationale for the combination of vildagliptin and metformin}

Because an incretin-based therapy acts by different mechanisms than metformin, combined therapy with metformin and a DPP4 inhibitor like vildagliptin was expected to be of considerable interest for the treatment of type 2 diabetes. Firstly, additive effects on plasma glucose lowering should be seen, which was first demonstrated with a combination of metformin and GLP-1 infusion in T2DM patients (Zander et al 2001). Furthermore, beyond the additive effects of the drugs, the attractive potential of this combination would be to achieve the glucose lowering effect with beneficial effects on $\beta$-cell function, without promoting weight gain or increasing the risk of hypoglycemia and without exacerbating the GI side effects of metformin. Clinical studies have indeed confirmed these expectations as outlined below.

An additional interesting aspect regarding the combination of metformin and a DPP4 inhibitor comes from the following recent research findings. Firstly, it was indicated that metformin increases plasma active GLP-1 in obese nondiabetic subjects, suggesting that metformin may have the 
additional property of inhibiting DPP IV activity (Mannucci et al 2001). This increase in active GLP-1 with metformin was further confirmed by a number of studies, while the underlying mechanism is still the subject of debate: the increase could reflect a stimulation of GLP-1 secretion from intestinal L cells, an inhibition of renal GLP-1 excretion or an increased transcription/translation of the proglucagon gene, as well as an effective inhibition of DPP IV activity (Zander et al 2001; Hinke et al 2002 a, b; Green et al 2006; Lindsay et al 2005).

The clinical potential of this mechanistic research further emerged when Dunning et al (Dunning et al 2006) compared the effects of vildagliptin on plasma levels of intact GLP-1 in drug-naïve patients with T2DM versus patients receiving concomitant metformin. Relative to patients receiving no concomitant $\mathrm{OAD}$, the effects of vildagliptin to increase plasma levels of both fasting and postprandial active GLP-1 were clearly and consistently enhanced in patients receiving concomitant metformin, a finding that likely extends to DDP4 inhibitors in general (Migoya et al 2007). The fact that vildagliptin substantially enhances the incretin effect in patients receiving concomitant metformin may underlie the pronounced efficacy of vildagliptin to decrease FPG, PPG and HbA1c in metformin-treated patients, as further discussed below.

\section{Clinical data on combination therapy of vildagliptin and metformin}

The efficacy of a drug when combined with other agents can be different from that of the same drug prescribed as monotherapy: when used in combination, most drugs reduce $\mathrm{HbA}_{1 \mathrm{c}}$ to a lesser extent than in monotherapy (DeFronzo and Goodman 1995). Furthermore, patients failing metformin monotherapy could have different characteristics and show a different response to hypoglycemic agents. Therefore, to reliably assess the efficacy of a new drug in combination with metformin, it is important to get data in patients insufficiently controlled with metformin monotherapy at stable, maximally tolerated doses. The efficacy and safety of the vildagliptin/metformin combination was studied accordingly in 2 placebo-controlled and 1 active-controlled trials.

The combination of vildagliptin plus metformin was initially evaluated in a 12-week phase II study with a 40-week, double-blind, placebo-controlled extension (Ahren et al $2004 a)$. In this population starting from a relatively low baseline $\mathrm{HbA}_{1 \mathrm{c}}$ of $7.6 \%$ and treated with metformin for a mean duration of 28 months and at a mean daily dose of $1.8 \mathrm{~g} /$ day, vildagliptin $50 \mathrm{mg}$ daily added to metformin reduced mean $\mathrm{HbA}_{1 \mathrm{c}}$ by $1.1 \%$ relative to metformin/placebo after 52 weeks of treatment $(p<0.001)$. This reflected deterioration of glycemic control in patients receiving metformin alone and a stable HbA1c of $7.1 \%$ maintained from week 12 to week 52 in patients treated with vildagliptin plus metformin, suggesting that the addition of vildagliptin prevented the progressive deterioration in glucose control seen in patients treated with metformin/placebo (Figure 1). The percentage of patients achieving the target of $\mathrm{HbA}_{1 \mathrm{c}}<7 \%$ at study end was $41.7 \%$ with vildagliptin plus metformin and $10.7 \%$ with placebo plus metformin (significant between-group difference) and the percentage of patients achieving a target of $\leq 6.5 \%$ was $21.4 \%$ with vildagliptin versus none with placebo. Two patients receiving vildagliptin during the core phase (out of 107 patients) experienced one episode of hypoglycemia and there were no hypoglycemic episodes during the extension. The lowering of fasting plasma glucose (FPG) from baseline persisted in patients who took vildagliptin $50 \mathrm{mg}$ qd plus metformin, and was significantly greater than in those taking placebo plus metformin (between group difference of $1.1 \mathrm{mmol} / \mathrm{L})$. Body weight was unchanged with vildagliptin, showing no difference to placebo $(+0.04 \mathrm{~kg})$. Fasting triglycerides, as well as total and LDL cholesterol, were modestly improved with vildagliptin compared to placebo. Interestingly, additional analyses showed that the maintenance of efficacy over 52 weeks was associated with a sustained improvement in both insulin secretion and dynamic insulin sensitivity (Ahren et al 2005). Furthermore, vildagliptin significantly improved the efficiency of insulin processing by the $\beta$-cells, providing further evidence that vildagliptin treatment ameliorates abnormal $\beta$-cell function in patients with T2DM (Ahren et al 2007).

The combination of vildagliptin plus metformin was further evaluated in a 24-week phase 3 study conducted in patients with inadequate glycemic control $\left(\mathrm{HbA}_{1 \mathrm{c}} 7.5 \%-11 \%\right)$ despite a stable metformin dose ( $\geq 1500 \mathrm{mg} /$ day, mean daily dose of $2100 \mathrm{mg}$ with a mean duration of metformin use of 17 months) (Bosi et al 2007). Enrollees were randomized to vildagliptin $50 \mathrm{mg}$ daily (given as $50 \mathrm{mg} \mathrm{qd}, \mathrm{n}=177$ ), vildagliptin $100 \mathrm{mg}$ daily (given as $50 \mathrm{mg}$ bid, $\mathrm{n}=185$ ), or placebo $(\mathrm{n}=182)$. The demographic and diabetic background characteristics of the 3 groups were well balanced at baseline, with a mean age of 54 years, a mean BMI of $32.8 \mathrm{~kg} / \mathrm{m}^{2}$, a mean disease duration of 6.2 years and a mean $\mathrm{HbA}_{1 \mathrm{c}}$ of $8.4 \%$ (Table 1 ). Relative to placebo the addition of vildagliptin to metformin resulted in significant and dose-related reductions in $\mathrm{HbA}_{1 \mathrm{c}}$ $(-1.1 \pm 0.1 \%$ and $-0.7 \pm 0.1 \%$ with vildagliptin $100 \mathrm{mg}$ daily 


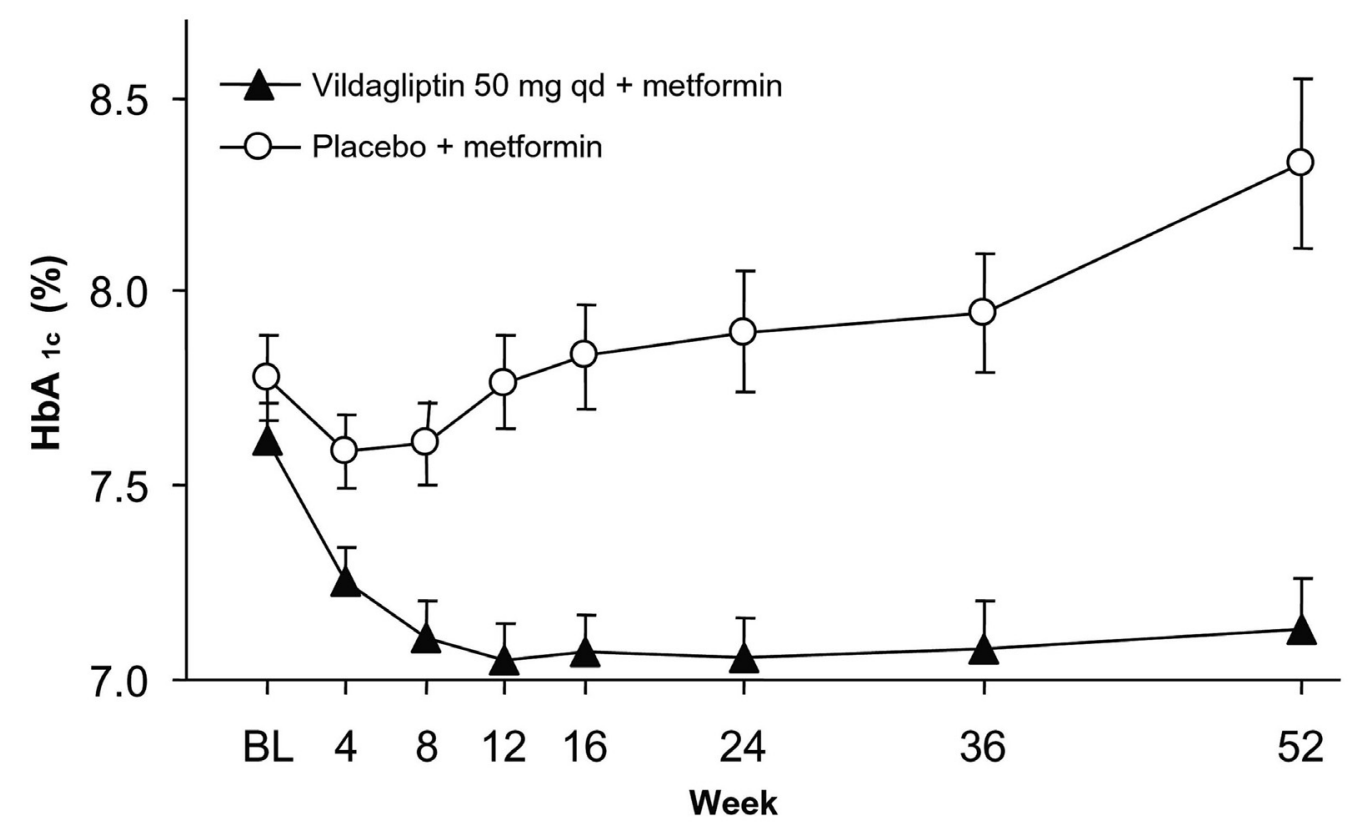

Figure I Mean $( \pm \mathrm{SE}) \mathrm{HbA}_{\mathrm{Ic}}$ during 52-week treatment with vildagliptin (50 mg qd, closed triangles, $\left.\mathrm{n}=42\right)$ and placebo (open circles, $\left.\mathrm{n}=29\right)$ in metformin-treated patients with T2DM. The between-group difference in HbAlc from baseline to endpoint was $-\mathrm{I} . \mathrm{I} \pm 0.2 \%(\mathrm{p}<0.000 \mathrm{I})$ (Ahren et al 2004a). Copyright $@$ American Diabetes Association. From Diabetes Care ${ }^{\circledR}$,Vol. 27, 2004; 2874-80. Modified with permission from The American Diabetes Association.

and $50 \mathrm{mg}$ daily, respectively; $\mathrm{p}<0.001$ vs placebo for both), and in fasting plasma glucose $(-1.7 \pm 0.3 \mathrm{mmol} / \mathrm{L}[\mathrm{p}<0.001$ vs placebo] and $-0.8 \pm 0.3 \mathrm{mmol} / \mathrm{L}[\mathrm{p}=0.003$ vs placebo], respectively). The percentage of patients achieving the target of $\mathrm{HbA}_{1 \mathrm{c}}<7 \%$ at study end was $35.5 \%$ with vildagliptin $100 \mathrm{mg}$ daily plus metformin compared to $9.4 \%$ with placebo plus metformin and percentage of patients achieving a target of $\leq 6.5 \%$ was $18.2 \%$ with vildagliptin $100 \mathrm{mg}$ daily plus metformin versus $3.1 \%$ with placebo plus metformin (both $\mathrm{p}<0.001)$. In addition, treatment with vildagliptin elicited significant reductions from baseline in 2-hour postprandial glucose relative to placebo: $-2.3 \pm 0.6 \mathrm{mmol} / \mathrm{L}$ and $-1.9 \pm$ $0.6 \mathrm{mmol} / \mathrm{L}$ with vildagliptin $100 \mathrm{mg}$ and $50 \mathrm{mg}$ daily ( $p=0.001$ vs placebo for both). Again, these effects were associated with significant improvements in measures of $\beta$-cell function: the $\beta$-cell function index, expressed as insulin secretory rate/glucose (Pratley et al 2007b), increased significantly by 3 -fold relative to placebo in both vildagliptin groups ( $p<0.001$ ). In patients aged $\geq 65$ years, a pre-planned subgroup analysis showed a mean reduction from baseline in $\mathrm{HbA}_{1 \mathrm{c}}$ of $1.3 \pm 0.2 \%$ with vildagliptin $100 \mathrm{mg} / \mathrm{d}$ compared to a small increase of $0.2 \pm 0.1 \%$ with placebo.

Vildagliptin did not induce body weight gain (change from baseline of +0.21 and $-0.38 \mathrm{~kg}$ with vildagliptin 100 and 50 $\mathrm{mg}$ daily, respectively, compared to $-1.02 \mathrm{~kg}$ with placebo). The effect of vildagliptin on fasting lipids was largely neutral, with the exception of fasting triglycerides, which increased less in the vildagliptin treatment groups than in the placebo group (difference from placebo ranging from $14.5 \%$ to $18.4 \%$ ). Effects of vildagliptin $100 \mathrm{mg}$ daily and placebo on blood pressure (BP) were compared and showed modest improvements in BP in both groups with a significant benefit of vildagliptin versus placebo added to metformin (Bosi et al 2007b).

The incidence of reported adverse events (AEs) was similar among groups $(65.0 \%, 63.3 \%$, and $63.5 \%$ of patients receiving vildagliptin $100 \mathrm{mg}$ daily, $50 \mathrm{mg}$ daily, or placebo, respectively). GI side effects were reported less frequently in the vildagliptin treatment groups $(14.8 \%$ and $9.6 \%$ in the 100- and 50-mg daily groups, respectively) than in the placebo group (18.2\%). One patient in each of the 3 groups experienced a mild hypoglycemic event, which did not lead to discontinuation. Discontinuations due to AEs were overall marginally more frequent with vildagliptin (4.4\% and $4.5 \%$ respectively with 100 and $50 \mathrm{mg} / \mathrm{d})$ than placebo $(2.2 \%)$ (not driven by any specific AE), while serious AEs (SAEs) were marginally more common with placebo (4.4\%) than with vildagliptin (2.7\% and $2.3 \%$ with 100 and $50 \mathrm{mg}$ daily, respectively), and there were no deaths.

An additional active-controlled study (Bolli et al 2008) assessed the combination therapy of vildagliptin and metformin: a 24-week, multicenter, double-blind, randomized study, comparing vildagliptin (100 mg daily, given as equally-divided doses, $\mathrm{n}=295)$ and pioglitazone $(30 \mathrm{mg}$ daily, given as a single qd dose, $n=281$ ) in patients with 
Table I Patients' baseline characteristics: addition of vildagliptin in patients with inadequate glycemic control on maximum tolerated doses of metformin alone

\begin{tabular}{|c|c|c|c|c|c|c|c|}
\hline & \multicolumn{2}{|c|}{$\begin{array}{l}\text { Study I }{ }^{\mathrm{a}} \\
\text { Extension population }\end{array}$} & \multicolumn{3}{|c|}{$\begin{array}{l}\text { Study } 2^{\mathrm{b}} \\
\text { Randomized population }\end{array}$} & \multicolumn{2}{|c|}{$\begin{array}{l}\text { Study } 3^{c} \\
\text { Randomized population }\end{array}$} \\
\hline & $\begin{array}{l}\text { Vilda } 50 \mathrm{mg} \\
\text { qd + Met }\end{array}$ & $\mathrm{PBO}+\mathrm{Met}$ & $\begin{array}{l}\text { Vilda } 50 \mathrm{mg} \\
\text { qd + Met }\end{array}$ & $\begin{array}{l}\text { Vilda } 50 \mathrm{mg} \\
\text { bid + Met }\end{array}$ & $\mathrm{PBO}+\mathrm{Met}$ & $\begin{array}{l}\text { Vilda } 50 \mathrm{mg} \\
\text { bid + Met }\end{array}$ & $\begin{array}{l}\text { Pio } 30 \mathrm{mg} \\
\text { qd + Met }\end{array}$ \\
\hline $\mathrm{N}$ & 42 & 29 & 143 & 143 & 130 & 295 & $28 I$ \\
\hline $\begin{array}{l}\text { Age (years) } \\
(\text { mean } \pm S D)\end{array}$ & $58.4 \pm 9.2$ & $54.3 \pm 12.2$ & $54.3 \pm 9.7$ & $53.9 \pm 9.5$ & $54.5 \pm 10.3$ & $56.3 \pm 9.3$ & $57.0 \pm 9.7$ \\
\hline Male/Female (\%) & $62 / 38$ & $76 / 24$ & $57 / 43$ & $62 / 38$ & $53 / 47$ & $62 / 38$ & $64 / 36$ \\
\hline $\begin{array}{l}\mathrm{BMI}\left(\mathrm{kg} / \mathrm{m}^{2}\right) \\
(\text { mean } \pm \mathrm{SD})\end{array}$ & $29.6 \pm 3.7$ & $29.9 \pm 3.6$ & $32.1 \pm 5.3$ & $32.9 \pm 5.0$ & $33.2 \pm 6.1$ & $32.2 \pm 5.6$ & $32.1 \pm 5.1$ \\
\hline $\mathrm{HbA}_{\mathrm{Ic}}($ mean $\pm \mathrm{SD})$ & $7.6 \pm 0.6$ & $7.8 \pm 0.6$ & $8.4 \pm 0.9$ & $8.4 \pm 1.0$ & $8.3 \pm 0.9$ & $8.4 \pm 1.0$ & $8.4 \pm 0.9$ \\
\hline $\begin{array}{l}\text { FPG }(\mathrm{mmol} / \mathrm{L}) \\
(\text { mean } \pm \mathrm{SD})\end{array}$ & $9.6 \pm 1.6$ & $10.1 \pm 1.8$ & $9.7 \pm 2.2$ & $9.9 \pm 2.56$ & $10.0 \pm 2.35$ & $10.9 \pm 2.6$ & $11.0 \pm 2.7$ \\
\hline $\begin{array}{l}\text { Duration of T2DM } \\
\text { (years) (mean } \pm S D)\end{array}$ & $5.8 \pm 4.2$ & $4.6 \pm 3.6$ & $6.8 \pm 5.5$ & $5.8 \pm 4.7$ & $6.2 \pm 5.3$ & $6.4 \pm 4.9$ & $6.4 \pm 5.2$ \\
\hline
\end{tabular}

aStudy I: A 52-week study of vildagliptin $50 \mathrm{mg}$ daily added to metformin (Ahren et al 2004a).

bStudy 2: A 24-week study of vildagliptin (50 mg daily or $100 \mathrm{mg}$ daily) or placebo added to metformin (Bosi et al 2007a).

'Study 3: A 24-week study of vildagliptin ( $100 \mathrm{mg}$ daily) or pioglitazone (30 mg daily) added to metformin (Bolli et al 2008).

Abbreviations: Vilda, vildagliptin; Met, metformin; PBO, placebo; Pio, pioglitazone.

inadequate glycemic control $\left(\mathrm{HbA}_{1 \mathrm{c}} 7.5 \%-11 \%\right)$ despite metformin monotherapy (used for an average of 43 months) at a stable dose (mean dose at baseline $>2000 \mathrm{mg} /$ day).

The groups were well balanced at baseline, with a mean age, BMI, $\mathrm{HbA}_{1 \mathrm{c}}$, and $\mathrm{FPG}$ of $\sim 57$ years, $32.1 \mathrm{~kg} / \mathrm{m}^{2}, 8.4 \%$, and $10.9 \mathrm{mmol} / \mathrm{L}$, respectively. Patients were predominantly Caucasian, with mean disease duration of 6.4 years. When added to a stable dose of metformin, both vildagliptin $100 \mathrm{mg}$ and pioglitazone $30 \mathrm{mg}$ daily were equally effective in decreasing $\mathrm{HbA}_{1 \mathrm{c}}$ (by $0.9 \pm 0.1 \%$ and $1.0 \pm 0.1 \%$, respectively) from identical baseline values $(8.4 \pm 0.1 \%)$ with statistical non-inferiority of vildagliptin to pioglitazone being established (Figure 2). The decrease in $\mathrm{A} 1 \mathrm{C}$ in the pre-defined subgroup of patients with baseline A1C $>9.0 \%$ was more substantial, as expected, and similar in vildagliptin-treated patients (baseline $=9.8 \%$; mean change $=-1.5 \pm 0.2 \%$ ) and in those receiving pioglitazone (baseline $=9.7 \%$; mean change $=-1.5 \pm 0.2 \%$ ). The percentage of patients who achieved the endpoint of $\mathrm{HbA}_{1 \mathrm{c}} \leq 6.5 \%$ was comparable in those receiving vildagliptin $(19.7 \%)$ and pioglitazone (17.9\%). Pioglitazone decreased FPG $(-2.1 \pm 0.1 \mathrm{mmol} / \mathrm{L})$ to a greater extent than vildagliptin $(1.4 \pm 0.1 \mathrm{mmol} / \mathrm{L})$, but only pioglitazone increased body weight $(+1.9 \pm 0.2 \mathrm{~kg}$ : betweengroup difference $=-1.6 \pm 0.3 \mathrm{~kg}, \mathrm{p}<0.001)$ (Figure 3). In the more obese patients (with BMI $>35 \mathrm{~kg} / \mathrm{m}^{2}$ ), the mean change in body weight from baseline to endpoint was $+0.1 \pm 0.5 \mathrm{~kg}$ in patients receiving vildagliptin (baseline $=110.6 \mathrm{~kg}, \mathrm{n}=73$ ), and $+2.6 \pm 0.5 \mathrm{~kg}$ in pioglitazone-treated patients (baseline $=110.3 \mathrm{~kg}, \mathrm{n}=70$; between-treatment difference $-2.5 \pm 0.7 \mathrm{~kg}[\mathrm{p}<0.001])$. On the other hand, the efficacy tended to be more pronounced with pioglitazone in the obese patients (mean baseline BMI of $36 \mathrm{~kg} / \mathrm{m}^{2}$ ) with a mean change in $\mathrm{HbA}_{\mathrm{lc}}$ of $-1.2 \% \pm 0.1 \%$ versus $-0.8 \% \pm 0.1 \%$ with vildagliptin, while the reverse was true in non obese patients (mean baseline BMI $27 \mathrm{~kg} / \mathrm{m}^{2}$ ) in whom the decrease in $\mathrm{HbA}_{1 \mathrm{c}}$ was somewhat greater in those receiving vildagliptin $(1.0 \% \pm 0.1 \%)$ than pioglitazone $(0.7 \% \pm 0.1 \%)$.

Fasting lipid levels were similar in the two treatment groups at baseline. Total-cholesterol, LDL-cholesterol and non-HDL cholesterol decreased in patients receiving vildagliptin and increased in pioglitazone-treated patients (with between-group differences of $-6.9 \% \pm 1.3 \%$ for total cholesterol, $-10.2 \% \pm 2.4 \%$ for LDL cholesterol, and $-4.9 \% \pm 1.9 \%$ for non-HDL cholesterol, all $\mathrm{p}<0.001$ ). Conversely, fasting triglycerides decreased more (between-treatment difference of $9.3 \% \pm 3.2 \%, p=0.004$ ) and HDL-cholesterol increased more (between-treatment difference of $-13.8 \% \pm 1.6 \%, \mathrm{p}<0.001)$ in pioglitazone-treated patients. AEs were reported by $60 \%$ of patients receiving vildagliptin and by $56.4 \%$ of pioglitazone-treated patients; SAEs were reported by $2.0 \%$ and $4.6 \%$ of patients receiving vildagliptin and pioglitazone, respectively. Mild hypoglycemia was reported by 1 patient in the vildagliptin group $(0.3 \%)$ and by no patient receiving pioglitazone (Bolli et al 2008).

In summary, the 3 double-blind, controlled studies evaluating combination therapy with vildagliptin and metformin showed statistically significant and clinically meaningful reductions in $\mathrm{HbA}_{1 \mathrm{c}}$ when vildagliptin was added to metformin of $\sim 1 \%$ (Figure 2), that were evident across all demographic and disease subgroups. In patients with T2DM 


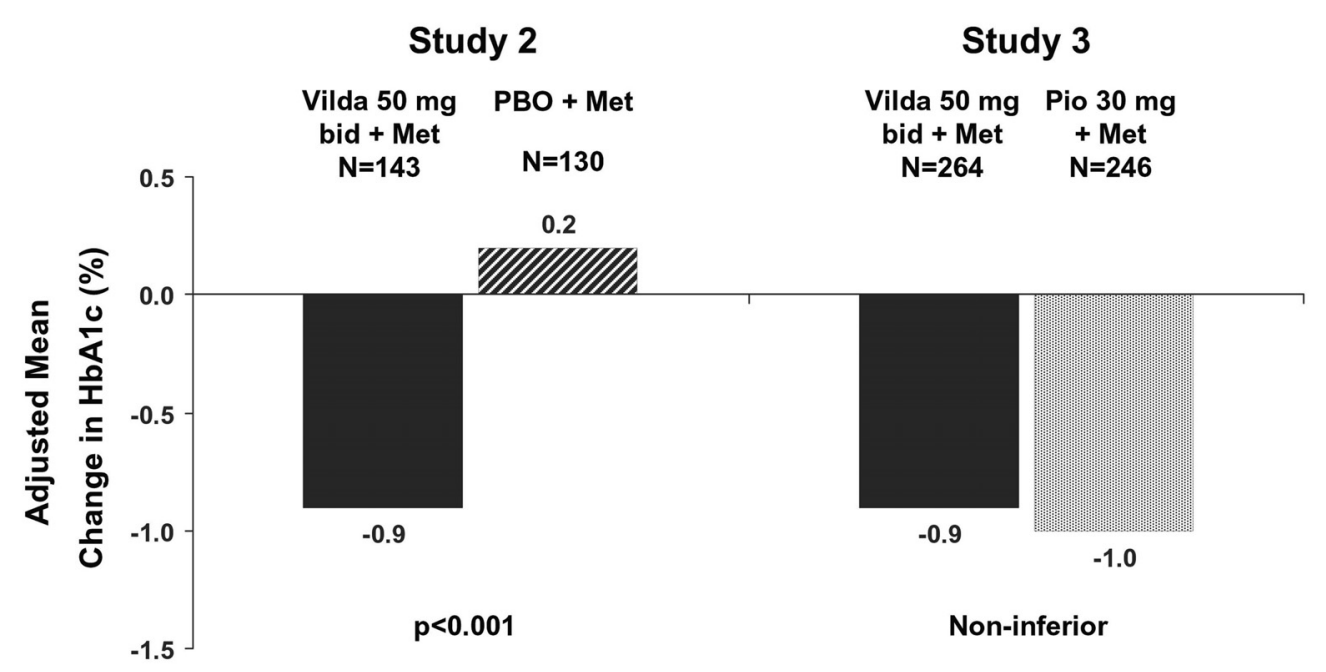

Figure 2 Study 2 - Adjusted mean change from baseline to endpoint in $\mathrm{HbA}_{\mathrm{Ic}}$ after 24 weeks of treatment with vildagliptin (50 mg bid) or placebo in metformin-treated patients with T2DM ( $p<0.00$ I) (Bosi et al 2007a).

Study 3 -Adjusted mean change from baseline to endpoint in $\mathrm{HbA}_{\mathrm{lc}}$ after 24 weeks of treatment with vildagliptin (50 mg bid) or pioglitazone (30 mg qd) in metformin-treated patients with T2DM; the between group difference was $0.10 \pm 0.08 \%$ ( $95 \mathrm{Cl}:-0.05,-0.26)$ (Bolli et al 2008).

inadequately controlled with metformin, the addition of vildagliptin (100 mg daily) was equally effective as that of pioglitazone (30 mg daily). Efficacy was well preserved over 52 weeks in the placebo-controlled extension. Fasting and post prandial plasma glucose were significantly reduced; and the beneficial effects on glucose control was clearly accompanied by consistent improvements of parameters for $\beta$-cell function. The effects on fasting lipids were neutral and, in contrast to the pioglitazone/metformin combination (especially in the more obese patients) there was no weight gain. Overall the tolerability profile was good, with in particular no exacerbation of GI tolerability and there was no increased risk of hypoglycemia with vildagliptin and metformin combination therapy.

\section{Vildagliptin as a fixed combination product with metformin - opportunities for improvement of adherence}

While early and aggressive treatment with multiple drug combinations becomes increasingly common in the management of T2DM, adding more medications may however translate into reduced adherence to treatment. Subsequently, efforts have been made to simplify the treatment regimen with fixedcombination tablets to help improving treatment adherence in patients with T2DM who frequently take multiple medication. For this reason, vildagliptin and metformin have recently been made available in a single tablet $\left(\right.$ Eucreas $\left.^{\circledR}\right)$.

This new galenical formulation combines fixed doses of vildagliptin and metformin in 2 dosage strengths of 50/850 and 50/1000 mg of vildagliptin and metformin, and was developed based on 4 additional pharmacokinetic (PK) studies: 3 cross-over design PK studies in healthy subjects, to assess if the fixed combination tablet was bioequivalent to the free combination of the active components, and 1 cross-over design PK study to assess the effect of food on the absorption of the fixed combination tablet.

These PK studies demonstrated that the fixed combination tablets are bioequivalent to the co-administered vildagliptin and metformin as free combinations. The efficacy and safety of the new combination tablet can thus be based on the data already available in T2DM patients insufficiently controlled with metformin monotherapy.

\section{What is known with compliance to OADs}

Poor adherence to a treatment regimen is common (Osterberg and Blaschke 2005). At least $50 \%$ of patients do not fully benefit from their treatment due to inadequate compliance. This contributes to explain the gap between the implementation of clinical guidelines and the expected benefits. Poor compliance is a particular problem in asymptomatic and chronic diseases such as T2DM (Cramer 2004) contributing to substantial increases in morbidity and cost, with a higher risk of hospitalizations (Balkrishnan et al 2003; Lau and Nau 2004). In T2DM, poor medication adherence is associated with inadequate glycemic control ( Schectman et al 2002; Pladevall et al 2004): even after adjusting for demographic and clinical characteristics, a $10 \%$ decrease in adherence to 


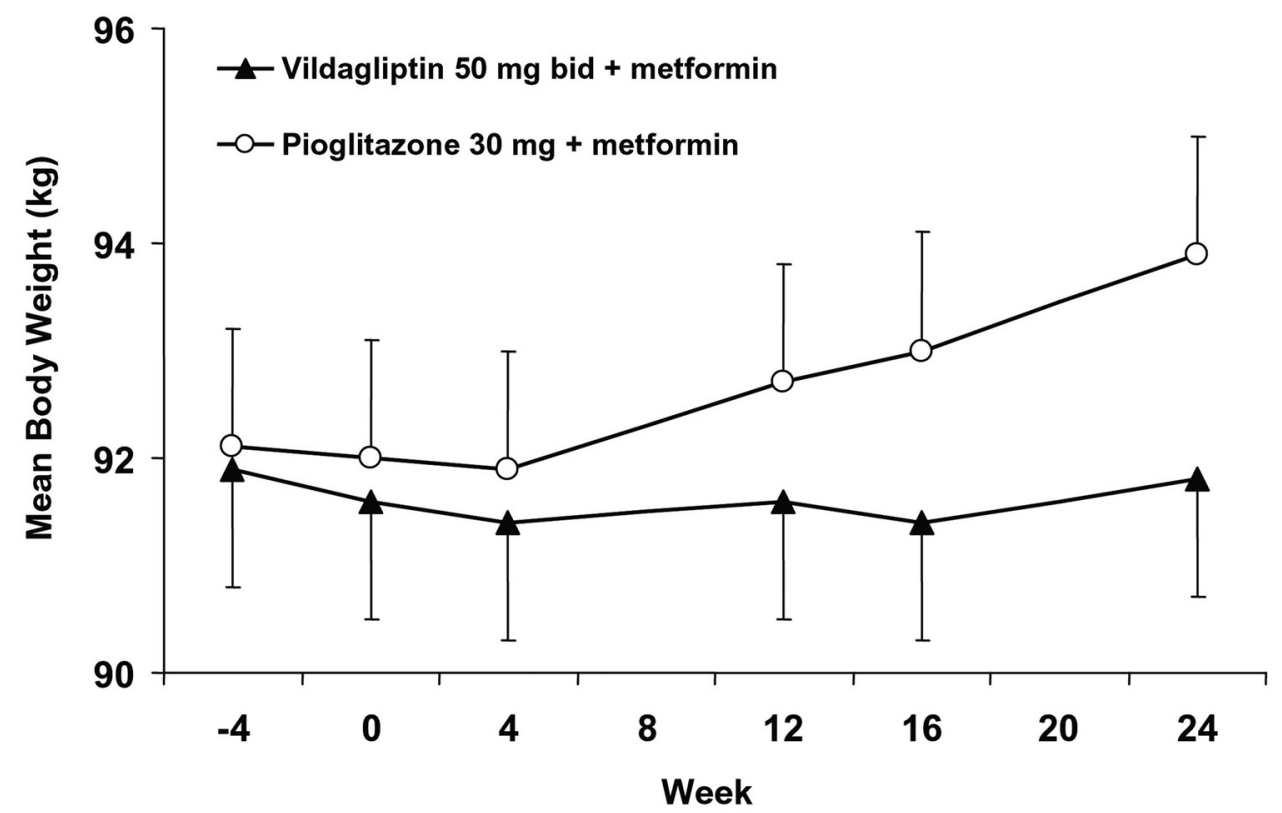

Figure 3 Study 3 -Time-course of mean body weight during 24 -week treatment with vildagliptin ( $50 \mathrm{mg}$ bid, closed triangles, $\mathrm{n}=264)$ or pioglitazone ( $30 \mathrm{mg}$ qd, open circles, $\mathrm{n}=246$ ) in T2DM patients continuing their previous stable metformin dose regimen (Derived from data of Bolli et al 2008).

metformin was significantly associated with an increase of 0.14\% in HbA1c (Pladevall et al 2004).

Among all the factors potentially related to adherence (including demographic, psychological, social, health care provider and medical system factors), polypharmacy and the complexity of a regimen (with the number of dose-administrations) are known to be 2 important determinants of poor compliance (Paes et al 1997; Balkrishnan et al 2003). Diabetic patients are frequently polymedicated, especially older patients with multiple co morbidities (Pratley et al 2007a). They most often need medications for cardioprotection, hypertension and hyperlipidemia in addition to diabetes. While the question whether this polypharmacy adversely affects adherence among diabetic patients is still under some debate (Grant et al 2003), most studies have shown that reducing the pill burden resulted in improved compliance (Dezii et al 2002; Melikian et al 2002; Kardas 2005; Bangalore et al 2007). In particular, a large prospective study that evaluated compliance based on self reported standard questionnaire has suggested the relevance of reducing the daily dosing frequency of oral antidiabetic agents, in order to improve compliance and metabolic control (Guillausseau 2003).

Therefore, one practical way of enhancing adherence is to make the treatment regimen simpler with fixed-combination products. Given the importance of medication adherence for health outcomes of diabetes care (Pladevall et al 2004), it is surprising that only few studies have looked at the effects on adherence of fixed combination drugs versus individual drugs. One recent meta-analysis (which included 2 studies in the diabetic population) showed that fixed-dose combination reduce the risk of non-compliance by $26 \%$ compared to free-drug combination regimens (pooled relative risk [RR] 0.74; 95\% confidence interval [CI], 0.69-0.80; $p<0.0001)$ (Bangalore et al 2007).

Thus, fixed-dose combination tablets may play an important role in T2DM to help improving medication compliance and the effectiveness of therapy, which should ultimately translate into better clinical outcomes.

\section{Conclusions and place in therapy}

The combination of vildagliptin and metformin, two oral antidiabetic agents with complementary mechanisms of action, provides superior efficacy and allows more patients to reach their glycemic targets compared to continuing metformin monotherapy, without increasing the risk of hypoglycemia, without exposing to weight gain and without altering common cardiovascular risk factors (hypertension and lipid profile). In addition, this combination has demonstrated favorable effects on pancreatic $\alpha$ - and $\beta$-cells. Whether the effect on parameters of $\beta$-cell function will translate in long term $\beta$-cell preservation, which may modify the course of the disease, remains to be shown by long-term clinical studies. The availability of vildagliptin and metformin in a single tablet (Eucreas ${ }^{\circledR}$ ) further enhances convenience and likely adherence to treatment.

As the glycemic targets recommended by guidelines are further lowered, many patients may remain inadequately 
treated because of the various limitations of the current therapies, such as the increased risk of hypoglycemia with sulfonylureas or the weight gain with TZDs.

Given its characteristics, Eucreas ${ }^{\circledR}$ will be a particularly appealing treatment option for moderately hyperglycemic patients who are relatively close to target (ie, HbAlc between 6.5 to $7.5 \%$ despite metformin) but for whom glucose control is not further tightened in order to avoid hypoglycemia or to limit weight gain. This new fixed-combination of vildagliptin and metformin could thus take a promising place in therapy and become the preferred combination with metformin in these mildly hyperglycemic patients and in older and more fragile individuals.

\section{References}

UKPDS 34. 1998. Effect of intensive blood-glucose control with metformin on complications in overweight patients with type 2 diabetes (UKPDS 34). UK Prospective Diabetes Study (UKPDS) Group. Lancet, 352:854-65.

Ahren B. 2006. Glucagon secretion in relation to insulin sensitivity in healthy subjects. Diabetologia, 49:117-22.

Ahren B, Gomis R, Standl E, et al. 2004a. Twelve- and 52-week efficacy of the dipeptidyl peptidase IV inhibitor LAF237 in metformin-treated patients with type 2 diabetes. Diabetes Care, 27:2874-80.

Ahren B, Landin-Olsson M, Jansson PA, et al. 2004b. Inhibition of dipeptidyl peptidase-4 reduces glycemia, sustains insulin levels, and reduces glucagon levels in type 2 diabetes. $J$ Clin Endocrinol Metab, 89:2078-84

Ahren B, Pacini G, Foley JE, et al. 2005. Improved meal-related beta-cell function and insulin sensitivity by the dipeptidyl peptidase-IV inhibitor vildagliptin in metformin-treated patients with type 2 diabetes over 1 year. Diabetes Care, 28:1936-40.

Ahren B, Pacini G, Tura A, et al. 2007. Improved meal-related insulin processing contributes to the enhancement of B-Cell Function by the DPP-4 inhibitor vildagliptin in patients with type 2 diabetes. Horm Metab Res, 39:826-9.

Ahrén B, Pratley RE, Soubt M, et al. 2008. Clinical measures of islet function: usefulness to characterize defects in diabetes. Curr Diabetes Rev (in Press).

Ayalasomayajula SP, Dole K, He YL, et al. 2007. Evaluation of the potential for steady-state pharmacokinetic interaction between vildagliptin and simvastatin in healthy subjects. Curr Med Res Opin, 23:2913-20.

Azuma K, Radikova Z, Mancino J, et al. 2007. Measurements of islet function and glucose metabolism with the DPP-4 inhibitor vildagliptin in patients with type 2 diabetes. J Clin Endocrinol Metab.

Bailey CJ, Turner RC. 1996. Metformin. N Engl J Med, 334:574-9.

Balas B, Baig MR, Watson C, et al. 2007. The dipeptidyl peptidase IV inhibitor vildagliptin suppresses endogenous glucose production and enhances islet function after single-dose administration in type 2 diabetic patients. J Clin Endocrinol Metab, 92:1249-55.

Balkrishnan R, Rajagopalan R, Camacho FT, et al. 2003. Predictors of medication adherence and associated health care costs in an older population with type 2 diabetes mellitus: a longitudinal cohort study. Clin Ther, 25:2958-71.

Bangalore S, Kamalakkannan G, Parkar S, et al. 2007. Fixed-dose combinations improve medication compliance: a meta-analysis. Am J Med, 120:713-19.

Bolli G, Dotta F, Rochotte E, et al. 2008. Efficacy and tolerability of vildagliptin vs. pioglitazone when added to metformin: a 24-week, randomized, double-blind study. Diabetes Obes Metab, 10:82-90.
Bosi E, Camisasca RP, Collober C, et al. 2007a. Effects of vildagliptin on glucose control over 24 weeks in patients with type 2 diabetes inadequately controlled with metformin. Diabetes Care, 30:890-5.

Bosi E, Shao Q, Cohen SE. 2007b. Improved blood pressure (BP) lowering in hypertensive patients (pts) with type 2 diabetes (T2DM) with vildagliptin combined with metformin compared with metformin alone. Diabetes, 56:A549.

Brown JB, Nichols GA, Perry A. 2004. The burden of treatment failure in type 2 diabetes. Diabetes Care, 27:1535-40.

Brown JB, Pedula K, Barzilay J, et al. 1998. Lactic acidosis rates in type 2 diabetes. Diabetes Care, 21:1659-63.

Burkey BF, Russell M, Wang K, et al. 2006. Vildagliptin displays slow tight-binding to dipeptidyl peptidase (DPP)-4, but not DPP-8 or DPP-9, Diabetologia, 49:477-8.

Butler AE, Janson J, Bonner-Weir S, et al. 2003. Beta-cell deficit and increased beta-cell apoptosis in humans with type 2 diabetes. Diabetes, $52: 102-10$.

Consoli A, Gomis R, Halimi S, et al. 2004. Initiating oral glucose-lowering therapy with metformin in type 2 diabetic patients: an evidence-based strategy to reduce the burden of late-developing diabetes complications. Diabetes Metab, 30:509-16.

Cook MN, Girman CJ, Stein PP, et al. 2007. Initial monotherapy with either metformin or sulphonylureas often fails to achieve or maintain current glycaemic goals in patients with Type 2 diabetes in UK primary care. Diabet Med, 24:350-8.

Cramer JA. 2004. A systematic review of adherence with medications for diabetes. Diabetes Care, 27:1218-24.

DeFronzo RA, Goodman AM. 1995. Efficacy of metformin in patients with non-insulin-dependent diabetes mellitus. The Multicenter Metformin Study Group. N Engl J Med, 333:541-9.

Dejager S, Razac S, Foley JE, et al. 2007. Vildagliptin in drug-naive patients with type 2 diabetes: a 24 -week, double-blind, randomized, placebocontrolled, multiple-dose study. Horm Metab Res, 39:218-23.

Dezii CM, Kawabata H, Tran M. 2002. Effects of once-daily and twice-daily dosing on adherence with prescribed glipizide oral therapy for type 2 diabetes. South Med J, 95:68-71.

Donnelly LA, Doney AS, Hattersley AT, et al. 2006. The effect of obesity on glycaemic response to metformin or sulphonylureas in Type 2 diabetes. Diabet Med, 23:128-33.

Dunning BE, Ligueros-Saylan M, D'Alessio DA, et al. 2006. Differential effects of DPP-4 inhibition on incretin hormone levels in drug-naive and metformin-treated patients with type 2 diabetes. Diabetologia, 49110-11.

Duttaroy A, Voelker F, Zhang X, et al. 2005. The DPP-4 inhibitor vildagliptin increases pancreatic beta cell mass in rodents. Diabetologia, 48:A178.

El Ouaghlidi A, Rehring E, Holst JJ, et al. 2007. The dipeptidyl peptidase 4 inhibitor vildagliptin does not accentuate glibenclamide-induced hypoglycemia but reduces glucose-induced glucagon-like peptide 1 and gastric inhibitory polypeptide secretion. J Clin Endocrinol Metab, 92:4165-71.

Fonseca V, Schweizer A, Albrecht D, et al. 2007. Addition of vildagliptin to insulin improves glycaemic control in type 2 diabetes. Diabetologia, $50: 1148-55$

Garber AJ, Camisasca RP, Jauffret S, et al. 2007a. Efficacy and tolerability of vildagliptin added to a sulfonylurea (SU) in patients with type 2 diabetes (T2DM). Diabetes, 56:A134.

Garber AJ, Schweizer A, Baron MA, et al. 2007b. Vildagliptin in combination with pioglitazone improves glycaemic control in patients with type 2 diabetes failing thiazolidinedione monotherapy: a randomized, placebocontrolled study. Diabetes Obes Metab, 9:166-74.

Golay A. 2007. Metformin and body weight. Int J Obes (Lond).

Goodarzi MO, Bryer-Ash M. 2005. Metformin revisited: re-evaluation of its properties and role in the pharmacopoeia of modern antidiabetic agents. Diabetes Obes Metab, 7:654-65.

Grant RW, Devita NG, Singer DE, et al. 2003. Polypharmacy and medication adherence in patients with type 2 diabetes. Diabetes Care, 26:1408-12. 
Green BD, Irwin N, Duffy NA, et al. 2006. Inhibition of dipeptidyl peptidase-IV activity by metformin enhances the antidiabetic effects of glucagon-like peptide-1. Eur J Pharmacol, 547:192-9.

Guillausseau PJ. 2003. Influence of oral antidiabetic drugs compliance on metabolic control in type 2 diabetes. A survey in general practice. Diabetes Metab, 29:79-81.

Halimi S. 2006. Metformin: 50 years old, fit as a fiddle, and indispensable for its pivotal role in type 2 diabetes management. Diabetes Metab, 32:555-6.

He YL, Sabo R, Riviere GJ, et al. 2007a. Effect of the novel oral dipeptidyl peptidase IV inhibitor vildagliptin on the pharmacokinetics and pharmacodynamics of warfarin in healthy subjects. Curr Med Res Opin, 23:1131-8.

He YL, Sabo R, Sunkara G, et al. 2007b. Evaluation of pharmacokinetic interactions between vildagliptin and digoxin in healthy volunteers. J Clin Pharmacol, 47:998-1004.

He YL, Sadler BM, Sabo R, et al. 2007c. The absolute oral bioavailability and population-based pharmacokinetic modelling of a novel dipeptidylpeptidase-IV inhibitor, vildagliptin, in healthy volunteers. Clin Pharmacokinet, 46:787-802.

He YL, Serra D, Wang Y, et al. 2007d. Pharmacokinetics and pharmacodynamics of vildagliptin in patients with type 2 diabetes mellitus. Clin Pharmacokinet, 46:577-88.

He YL, Wang Y, Bullock JM, et al. 2007e. Pharmacodynamics of vildagliptin in patients with type 2 diabetes during OGTT.J Clin Pharmacol, 47:633-41.

Hinke SA, Kuhn-Wache K, Hoffmann T, et al. 2002a. Metformin effects on dipeptidylpeptidase IV degradation of glucagon-like peptide-1. Biochem Biophys Res Commun, 291:1302-8.

Hinke SA, McIntosh CH, Hoffmann T, et al. 2002b. On combination therapy of diabetes with metformin and dipeptidyl peptidase IV inhibitors. Diabetes Care, 25:1490-1.

Kahn SE, Haffner SM, Heise MA, et al. 2006. Glycemic durability of rosiglitazone, metformin, or glyburide monotherapy. $N$ Engl $J$ Med, 355:2427-43.

Kahn SE, Prigeon RL, McCulloch DK, et al. 1993. Quantification of the relationship between insulin sensitivity and beta-cell function in human subjects. Evidence for a hyperbolic function. Diabetes, 42:1663-72.

Kardas P. 2005. The DIACOM study (effect of DosIng frequency of oral Antidiabetic agents on the COMpliance and biochemical control of type 2 diabetes). Diabetes Obes Metab, 7:722-8.

Koro CE, Bowlin SJ, Bourgeois N, et al. 2004. Glycemic control from 1988 to 2000 among US adults diagnosed with type 2 diabetes: a preliminary report. Diabetes Care, 27:17-20.

Langley AK, Suffoletta TJ, Jennings HR. 2007. Dipeptidyl peptidase IV inhibitors and the incretin system in type 2 diabetes mellitus. Pharmacotherapy, 27:1163-80.

Lau DT, Nau DP. 2004. Oral antihyperglycemic medication nonadherence and subsequent hospitalization among individuals with type 2 diabetes. Diabetes Care, 27:2149-53.

Lindsay JR, Duffy NA, McKillop AM, et al. 2005. Inhibition of dipeptidyl peptidase IV activity by oral metformin in Type 2 diabetes. Diabet Med, 22:654-7.

Mannucci E, Ognibene A, Cremasco F, et al. 2001. Effect of metformin on glucagon-like peptide 1 (GLP-1) and leptin levels in obese nondiabetic subjects. Diabetes Care, 24:489-94.

Mari A, Sallas WM, He YL, et al. 2005. Vildagliptin, a dipeptidyl peptidaseIV inhibitor, improves model-assessed beta-cell function in patients with type 2 diabetes. J Clin Endocrinol Metab, 90:4888-94.

Mari A, Scherbaum WA, Nilsson PM, et al. 2007. Characterization of the influence of vildagliptin on model-assessed \{beta\}-cell function in patients with type 2 diabetes and mild hyperglycemia. $J$ Clin Endocrinol Metab.

Matikainen N, Manttari S, Schweizer A, et al. 2006. Vildagliptin therapy reduces postprandial intestinal triglyceride-rich lipoprotein particles in patients with type 2 diabetes. Diabetologia, 49:2049-57.
Melikian C, White TJ, Vanderplas A, et al. 2002. Adherence to oral antidiabetic therapy in a managed care organization: a comparison of monotherapy, combination therapy, and fixed-dose combination therapy. Clin Ther, 24:460-7.

Migoya EM, Miller J, Larson P, et al. 2007. Sitagliptin, a selective DPP-4 inhibitor, and metformin have complementary effects to increase active GLP-1 concentrations. Diabetes, 56:A74.

Nathan DM, Buse JB, Davidson MB, et al. 2008. Management of hyperglycaemia in type 2 diabetes mellitus: a consensus algorithm for the initiation and adjustment of therapy: Update regarding the thiazolidinediones. Diabetologia, 51:8-11.

Nathan DM, Buse JB, Davidson MB, et al. 2006. Management of hyperglycemia in type 2 diabetes: A consensus algorithm for the initiation and adjustment of therapy: a consensus statement from the American Diabetes Association and the European Association for the Study of Diabetes. Diabetes Care, 29:1963-72.

Nathan DM, Davidson MB, DeFronzo RA, et al. 2007. Impaired fasting glucose and impaired glucose tolerance: implications for care. Diabetes Care, 30:753-9.

Nichols GA, Alexander CM, Girman CJ, et al. 2006. Treatment escalation and rise in $\mathrm{HbAlc}$ following successful initial metformin therapy. Diabetes Care, 29:504-9.

Osterberg L, Blaschke T. 2005. Adherence to medication. $N$ Engl J Med, 353:487-97.

Paes AH, Bakker A, Soe-Agnie CJ. 1997. Impact of dosage frequency on patient compliance. Diabetes Care, 20:1512-17.

Pi-Sunyer FX, Schweizer A, Mills D, et al. 2007. Efficacy and tolerability of vildagliptin monotherapy in drug-naive patients with type 2 diabetes. Diabetes Res Clin Pract, 76:132-8.

Pladevall M, Williams LK, Potts LA, et al. 2004. Clinical outcomes and adherence to medications measured by claims data in patients with diabetes. Diabetes Care, 27:2800-5.

Pratley RE, Rosenstock J, Pi-Sunyer FX, et al. 2007a. Management of type 2 diabetes in treatment-naive elderly patients: benefits and risks of vildagliptin monotherapy. Diabetes Care, 30:3017-22.

Pratley RE, Schweizer A, Rosenstock J, et al. 2007b. Robust improvements in fasting and prandial measures of beta-cell function with vildagliptin in drug-naive patients: analysis of pooled vildagliptin monotherapy database. Diabetes Obes Metab.

Rosenstock J, Baron MA, Camisasca RP, et al. 2007a. Efficacy and tolerability of initial combination therapy with vildagliptin and pioglitazone compared with component monotherapy in patients with type 2 diabetes. Diabetes Obes Metab, 9:175-85.

Rosenstock J, Baron MA, Dejager S, et al. 2007b. Comparison of vildagliptin and rosiglitazone monotherapy in patients with type 2 diabetes: a 24-week, double-blind, randomized trial. Diabetes Care, 30:217-23.

Rosenstock J, Foley JE, Rendell M, et al. 2007c Effects of the DPP-4 inhibitor vildagliptin on incretin hormones, islet function, and postprandial glycemia in subjects with impaired glucose tolerance. Diabetes Care.

Schectman JM, Nadkarni MM, Voss JD. 2002. The association between diabetes metabolic control and drug adherence in an indigent population. Diabetes Care, 25:1015-21.

Scherbaum WA, Schweizer A, Mari A, et al. 2007. Efficacy and tolerability of vildagliptin in drug-naive patients with type 2 diabetes (T2DM) and mild hyperglycemia. Diabetes, 56:A134.

Schweizer A, Couturier A, Foley JE, et al. 2007. Comparison between vildagliptin and metformin to sustain reductions in $\mathrm{HbA}(1 \mathrm{c})$ over 1 year in drug-naive patients with Type 2 diabetes. Diabet Med, 24:955-61.

Stumvoll M, Nurjhan N, Perriello G, et al. 1995. Metabolic effects of metformin in non-insulin-dependent diabetes mellitus. $N$ Engl J Med, 333:550-4.

Sunkara G, Sabo R, Wang Y, et al. 2007. Dose proportionality and the effect of food on vildagliptin, a novel dipeptidyl peptidase IV inhibitor, in healthy volunteers. J Clin Pharmacol, 47:1152-8. 
Tahrani AA, Varughese GI, Scarpello JH, et al. 2007. Metformin, heart failure, and lactic acidosis: is metformin absolutely contraindicated? BMJ, 335:508-12.

Tourrel C, Bailbe D, Lacorne M, et al. 2002. Persistent improvement of type 2 diabetes in the Goto-Kakizaki rat model by expansion of the beta-cell mass during the prediabetic period with glucagon-like peptide-1 or exendin-4. Diabetes, 51:1443-52.

Turner RC, Cull CA, Frighi V, et al. 1999. Glycemic control with diet, sulfonylurea, metformin, or insulin in patients with type 2 diabetes mellitus: progressive requirement for multiple therapies (UKPDS 49). UK Prospective Diabetes Study (UKPDS) Group. JAMA, 281:2005-12.
Utzschneider KM, Tong J, Montgomery B, et al. 2008. The dipeptidyl peptidase4 inhibitor vildagliptin improves beta-cell function and insulin sensitivity in subjects with impaired fasting glucose. Diabetes Care, 31:108-13.

Virally M, Blickle JF, Girard J, et al. 2007.Type 2 diabetes mellitus: epidemiology, pathophysiology, unmet needs and therapeutical perspectives. Diabetes Metab, 33:231-44.

Vella A, Bock G, Giesler PD, et al. 2007.Effects of dipeptidyl peptidase-4 inhibition on gastrointestinal function, meal appearance, and glucose metabolism in type 2 diabetes. Diabetes, 56:1475-80.

Zander M, Taskiran M, Toft-Nielsen MB, et al. 2001. Additive glucoselowering effects of glucagon-like peptide-1 and metformin in type 2 diabetes. Diabetes Care, 24:720-5. 